\title{
Functional and Molecular Analysis of Proprioceptive Sensory Neuron Excitability in Mice
}

\author{
Jessica F. Madden ${ }^{1,2}$, Olivia C. Davis ${ }^{3}$, Kieran A. Boyle ${ }^{3}$, Jacqueline A. Iredale ${ }^{1,2}$, Tyler J. \\ Browne $^{1,2}$, Robert J. Callister ${ }^{1,2}$, Douglas W. Smith ${ }^{1,2}$, Phillip Jobling ${ }^{1,2}$, David I. Hughes ${ }^{3 *}$ \\ and Brett A. Graham ${ }^{1,2 *}$
}

${ }^{1}$ School of Biomedical Sciences and Pharmacy, Faculty of Health and Medicine, University of Newcastle, Callaghan, NSW, Australia, ${ }^{2}$ Hunter Medical Research Institute (HMRI), New Lambton Heights, NSW, Australia, ${ }^{3}$ Institute of Neuroscience Psychology, College of Medical, Veterinary and Life Sciences, University of Glasgow, Glasgow, United Kingdom

\section{OPEN ACCESS}

Edited by:

Jochen C. Meier,

Technische Universitat

Braunschweig, Germany

Reviewed by:

Judith Ann Strong,

University of Cincinnati, United States

Wenrui Xie,

University of Cincinnati, United States

${ }^{*}$ Correspondence:

David I. Hughes

david.i.hughes@glasgow.ac.uk

Brett A. Graham

brett.graham@newcastle.edu.au

Received: 18 October 2019 Accepted: 20 February 2020

Published: 05 May 2020

Citation:

Madden JF, Davies OC, Boyle KA, Iredale JA, Browne TJ, Callister RJ, Smith DW, Jobling P, Hughes DI and

Graham BA (2020) Functional and Molecular Analysis of Proprioceptive Sensory Neuron Excitability in Mice.

Front. Mol. Neurosci. 13:36. doi: 10.3389/fnmol.2020.00036
Neurons located in dorsal root ganglia (DRG) are crucial for transmitting peripheral sensations such as proprioception, touch, temperature, and nociception to the spinal cord before propagating these signals to higher brain structures. To date, difficulty in identifying modality-specific DRG neurons has limited our ability to study specific populations in detail. As the calcium-binding protein parvalbumin (PV) is a neurochemical marker for proprioceptive DRG cells we used a transgenic mouse line expressing green fluorescent protein (GFP) in PV positive DRGs, to study the functional and molecular properties of putative proprioceptive neurons. Immunolabeled DRGs showed a 100\% overlap between GFP positive (GFP+) and PV positive cells, confirming the PVeGFP mouse accurately labeled $\mathrm{PV}$ neurons. Targeted patch-clamp recording from isolated GFP+ and GFP negative (GFP-) neurons showed the passive membrane properties of the two groups were similar, however, their active properties differed markedly. All GFP+ neurons fired a single spike in response to sustained current injection and their action potentials (APs) had faster rise times, lower thresholds and shorter half widths. A hyperpolarization-activated current $\left(\mathrm{I}_{h}\right)$ was observed in all GFP+ neurons but was infrequently noted in the GFP- population (100\% vs. 11\%). For GFP+ neurons, I $I_{h}$ activation rates varied markedly, suggesting differences in the underlying hyperpolarization-activated cyclic nucleotide-gated channel (HCN) subunit expression responsible for the current kinetics. Furthermore, quantitative polymerase chain reaction (qPCR) showed the $\mathrm{HCN}$ subunits 2, 1, and 4 mRNA (in that order) was more abundant in GFP+ neurons, while HCN 3 was more highly expressed in GFP- neurons. Likewise, immunolabeling confirmed $\mathrm{HCN}$ 1, 2, and 4 protein expression in GFP+ neurons. In summary, certain functional properties of GFP+ and GFP- cells differ markedly, providing evidence for modality-specific signaling between the two groups. However,

\footnotetext{
Abbreviations: AP, Action Potential; Ct, Cycle Threshold; DH, Dorsal Horn; dNTP, Deoxynucleotide triphosphates; DRG, Dorsal Root Ganglia; DTT, Dithiothreitol; EGTA, ethylene glycol-bis $(\beta$-aminoethyl ether $)-\mathrm{N}, \mathrm{N}, \mathrm{N}^{\prime}, \mathrm{N}^{\prime}$-tetraacetic acid; GFP+, Green Fluorescent Protein Positive; GFP-, Green Fluorescent Protein Negative; HCN channel, hyperpolarizationactivated cyclic nucleotide-gated channel; $\mathrm{I}_{\mathrm{h}}$, Hyperpolarization-Activated Current; PBS, Phosphate Buffer Solution; PEG, Poly-Ethylene Glycol; PV, Parvalbumin; qPCR, Quantitative Polymerase Chain Reaction; RT, Reverse Transcription; $\mathrm{RT}+$, Reverse transcription with reverse transcriptase; RT-, Reverse transcription without reverse transcriptase; sACSF, Substituted Artificial Cerebrospinal Fluid; SEM, Standard Error of the Mean; TrkC, Tyrosine Receptor Kinase C; ZD7288, 4-(N-Ethyl-N-phenylamino)-1,2 dimethyl-6-(methylamino) pyrimidinium chloride.
} 
the GFP+ DRG population demonstrates considerable internal heterogeneity when hyperpolarization-activated cyclic nucleotide-gated channel (HCN channel) properties and subunit expression are considered. We propose this heterogeneity reflects the existence of different peripheral receptors such as tendon organs, muscle spindles or mechanoreceptors in the putative proprioceptive neuron population.

Keywords: parvalbumin, proprioception, dorsal root ganglia, sensory neuron, action potential, $I_{\mathrm{h}}$, HCN channel

\section{INTRODUCTION}

Our experience of somatosensory stimuli such as proprioception, pain, and touch, results from the detection of stimuli in the periphery by specialized receptors before the propagation of these signals along primary afferents. Primary afferents are the peripheral axons of pseudo-unipolar sensory neurons, whose cell bodies are clustered in dorsal root ganglia (DRG). These neurons are responsible for the transmission of sensory information into the dorsal horn $(\mathrm{DH})$ of the spinal cord and on to higher brain structures (Krames, 2014). Importantly, the anatomical positioning of the DRG outside the bloodnerve barriers of the central nervous system (CNS; Hu and McLachlan, 2002), has made sensory neurons a prime target for altering incoming sensory signals, especially those associated with nociception or pain. In particular, pharmacological (antiinflammatory steroids; Manchikanti, 2000; Vad et al., 2002), neuromodulation via electrical stimulation (Deer et al., 2013) and physical interventions such as ganglionectomy (Acar et al., 2008), radio-frequency ablation (Nash, 1986; de Louw et al., 2001) and pulsed-radio frequency activation (Van Zundert et al., 2007) have targeted sensory neurons to treat aberrant sensory signaling.

These above intervention strategies, however, do not account for the fact that sensory neurons are a heterogeneous population and carry different types of information. Most studies on DRG signaling have focused on nociception where nociceptive sensory neurons are distinguished by their small soma diameters, unmyelinated or lightly myelinated axons, and nociceptorspecific molecular markers such as transient receptor potential channels, TRPV1 and TRPA1 (Berta et al., 2017). The same approach has rarely been applied to the other modalities transmitted via sensory neurons such as proprioception, which relays information about movement and body position, from peripheral receptors located in muscle, tendon, and joints (Delhaye et al., 2018). Broadly, proprioceptive sensory neurons have been identified by their typically large neuron diameter, axon myelination and fast conduction velocities vs. the smaller sensory neurons that transmit light touch, temperature, and nociception (Lawson, 2005).

The calcium-binding protein parvalbumin (PV) has been used to mark proprioceptive sensory neurons in rodents because it is expressed in large diameter DRG cells (Celio, 1990; Ichikawa et al., 1994, 2004; Honda, 1995; Arber et al., 2000; de Nooij et al., 2013). PV is co-localized with Tyrosine receptor kinase C (Trk C) and Neurotrophin-3 proteins, which are linked to the development of proprioceptive receptors and their primary afferent neurons (Ernfors et al., 1994). Additionally, PV is selectively expressed in muscle spindle afferents in the periphery (Ichikawa et al., 2004). Together, these findings suggest PV is a reliable neurochemical marker for proprioceptive DRG neurons.

The rationale for characterizing the properties of DRG neuron subtypes is to characterize unique properties (e.g., ion channel subtypes) that might be targeted by therapeutic agents to alter sensory function. Similar to whole DRG targeting, this approach has been primarily applied in the pain field. For example, sodium channel blockers, which target specific channel types, are now in clinical trials (Haberberger et al., 2019). Recently, hyperpolarization-activated cyclic nucleotidegated $(\mathrm{HCN})$ channels and the hyperpolarization-activated current $\left(\mathrm{I}_{\mathrm{h}}\right)$ they mediate have been implicated in chronic pain states (Young et al., 2014; Tsantoulas et al., 2017; Lainez et al., 2019). This inward current is activated at hyperpolarized potentials and plays a role in adjusting resting membrane potential and generating rhythmic action potentials (APs; Hughes et al., 2013).

Interestingly, several studies have shown that $I_{h}$ is present in both large (presumably proprioceptive) and small (nociceptive) diameter neuronal populations. Their specific electrophysiological properties, however, are known to differ (Doan and Kunze, 1999; Gao et al., 2012). This suggests sensory neurons of different modalities express a unique pattern of hyperpolarization activated cyclic nucleotide gated $(\mathrm{HCN})$ channels that form tetramers and can be comprised of four distinct subunits, HCN1-4. Until recently, specific blocking agents for HCN subunits have not been described and their varied expression in a variety of tissues has limited our ability to target these channels. More recent studies, however, have reported subunit-specific blockers for HCN 1 and 2 over HCN 4, and these are currently being explored as a pain therapy (Dini et al., 2018). This work underscores the importance of understanding the expression pattern of HCN subunits across modality-specific sensory neuron populations. Importantly, the role of $I_{h}$ in proprioceptive sensory neurons, identified by characteristics other than size, has not yet been investigated.

To address this gap in our knowledge, we used a transgenic mouse line expressing green fluorescent protein (GFP) under a PV promoter gene (PV-eGFP) to study the functional and molecular properties of putative proprioceptive sensory neurons. Targeted-patch clamp recording was undertaken on isolated green fluorescent protein positive $(\mathrm{GFP}+)$ and green fluorescent protein negative (GFP-) sensory neurons to study their electrophysiological properties with a focus on $\mathrm{I}_{\mathrm{h}}$ currents in each population. We also undertook quantitative polymerase chain reaction (qPCR) and immunolabeling analysis to compare the expression of HCN subunits 1-4. 


\section{EXPERIMENTAL PROCEDURES}

\section{Dissection and Preparation of Dissociated Cells}

All experiments carried out at the University of Newcastle were in accordance with the Animal Research Act 1985 (NSW), under the guidelines of the National Health and Medical Research Council Code for the Care and Use of Animals for Scientific Purposes in Australia (2013). All experiments carried out in Glasgow were in accordance with the European Community directive 86/609/EEC and UK Animals (Scientific Procedures) Act 1986. We used a BAC transgenic BALB/c mouse (PVeGFP) generated to express an enhanced fluorescent protein (EGFP) under the control of the PV gene promoter (Meyer et al., 2002). The initial description of this mouse showed eGFP was selectively expressed in PV neurons throughout the nervous system. We have also used this mouse previously to characterize $\mathrm{PV}$-positive cells in the DH of the spinal cord (Hughes et al., 2012; Gradwell et al., 2017). Some experiments also used tissue from $\mathrm{C} 57 \mathrm{Bl} / 6$ mice for additional immunolabeling analysis.

Adult PVeGFP mice (eight male, nine female, average body weight $=24.4 \mathrm{~g}$ ) were deeply anesthetized with Ketamine (100 mg/kg i.p, Troy Laboratories, NSW, Australia) and sacrificed via rapid decapitation. Lumbar DRGs (L2-L6) from both sides were quickly removed with the aid of a dissecting microscope and placed in substituted artificial cerebrospinal fluid (sACSF) containing in mM: 236 Sucrose, $25 \mathrm{NaHCO}_{3}$, 11 glucose, $1 \mathrm{NaH}_{2} \mathrm{PO}_{4}, 2.5 \mathrm{KCl}, 2.5 \mathrm{CaCl}_{2}$, and $1 \mathrm{MgCl}$. For both electrophysiology and molecular experiments, DRGs were further dissociated into a single cell suspension. Briefly, DRGs were transferred to a HEPES based collagenase solution (10 mg/ml, Worthington Pty Ltd) for $40-60 \mathrm{~min}$ at $37^{\circ} \mathrm{C}$. Three flame polished glass Pasteur pipettes of decreasing diameter were then used to mechanically triturate the tissue and form a dissociated cell suspension ( $10 \times$ for each pipette diameter). The suspension was washed, and the supernatant replaced with a fresh HEPES solution. In patch-clamp recording experiments the cell suspension $(100 \mu \mathrm{l})$ was pipetted into a $22 \mathrm{~mm}$ plastic Petri dish. Recording commenced after cells had settled and adhered to the bottom of the Petri dish ( $\sim 15 \mathrm{~min})$, which also acted as the recording bath. For all gene expression analysis, the dissection and dissociation process remained the same, except all solutions, were prepared using diethylpyrocarbonate (DEPC) treated water $(0.1 \%$, Sigma Aldrich Pty Ltd), and underwent $24 \mathrm{~h}$ of agitation followed by autoclaving $\left(120^{\circ} \mathrm{C}\right.$ for $\left.30 \mathrm{~min}\right)$ to inactivate RNase enzymes.

\section{Immunolabeling}

The immunolabeling analysis was undertaken to examine the co-localization of native/endogenous PV and transgenic eGFP expression in DRGs from PVeGFP mice. The DRGs were removed as above (without dissociation) and emersion-fixed in $4 \%$ depolymerized paraformaldehyde (in phosphate buffer solution-PBS, $\mathrm{pH} 7.3$ ) for $2-3 \mathrm{~h}$. This tissue was subsequently treated with Dimethyl Sulfoxide (DMSO, Thermo Fisher Scientific) to permeabilize cellular membranes $(3 \times 15$ mins $)$ and then dehydrated in $100 \%$ ethanol $(3 \times 15$ mins, Thermo Fisher
Scientific). The tissue was submerged in poly-ethylene glycol (PEG-1000 molecular weight, Acros Organics) for $2 \mathrm{~h}$, before setting in PEG 1450 and subsequent sectioning $(20 \mu \mathrm{m})$ on a microtome. The sections were incubated in primary antibodies (polyclonal chicken anti-GFP 1:500, polyclonal rabbit anti-PV 1:400, Sapphire Bioscience Pty Ltd) diluted in a hypertonic PBS containing $10 \%$ donkey serum at room temperature for $15-18 \mathrm{~h}$. After washing $(3 \times 15$ mins in PBS), sections were incubated in species-specific secondary antibodies conjugated to $\mathrm{Cy} 3$ and FITC fluorophores (1:50, Jackson ImmunoResearch Pty Ltd) at room temperature for $2 \mathrm{~h}$. The secondary antibody was removed by washing $(3 \times 15 \mathrm{~min}$ in $\mathrm{PBS})$ and slices were mounted on glass slides using buffered glycerol $\left(33 \% 0.5 \mathrm{M} \mathrm{Na}_{2} \mathrm{CO}_{3} \mathrm{pH}\right.$ 8.6 in glycerol).

In addition to the above PV vs. GFP comparison, DRGs from wildtype $(\mathrm{C} 57 \mathrm{Bl} / 6)$ mice were processed to immunolabel and compare PV-expression with $\mathrm{HCN} 1, \mathrm{HCN} 2$, and $\mathrm{HCN}$ 4 expression. HCN 3 was not included in this analysis as antibodies to this subunit were found to only yield non-specific labeling. A total of three adult male C57Bl6 mice (20-22 g) were deeply anesthetized with pentobarbitone and perfused transcardially with $4 \%$ depolymerized formaldehyde. Lumbar DRG were removed and post-fixed in the same solution for an additional $2 \mathrm{~h}$. Free-floating sections of ganglia (60 $\mu \mathrm{m}$ thick) were cut on a vibratome and subsequently incubated in 50\% ethanol for $30 \mathrm{~min}$ to enhance antibody penetration. The sections were then incubated in a cocktail of primary antibodies containing guinea pig anti-PV (1:500; Frontier Institute Cat\# PV-GP-Af1000, RRID:AB_2336938) with either rabbit anti HCN1 (1:250; Alomone Labs Cat\# APC056, RRID:AB_2039900), rabbit anti-HCN2 (1:500; Alomone Labs Cat\# APC-030, RRID:AB_2313726) or mouse anti-HCN4 (diluted 1:500; UC Davis/NIH NeuroMab Facility Cat\# 73-150, RRID:AB_10673158). Immunolabeling for PV was visualized using a goat anti-guinea pig secondary antibody conjugated to Alexa488, and the HCN subunits were visualized using the tyramide signal amplification approach described previously (Hughes et al., 2012). All primary and secondary antibody cocktails were made up of $0.3 \mathrm{M}$ phosphate-buffered saline with $0.3 \%$ Triton $\mathrm{X}-100$. Sections were incubated in primary antibodies for $72 \mathrm{~h}$ and in secondary antibodies for $12-18 \mathrm{~h}$ at $4^{\circ} \mathrm{C}$.

Sections were cover-slipped and examined on an epifluorescence microscope (Olympus BX51) or confocal microscope (Zeiss LSM710, Hemel Hempstead, United Kingdom). Single images were captured using either a $10 \times$ or $20 \times$ objective in epifluorescence analysis. In confocal analysis, representative sections from each animal were scanned with image stacks collected using a $20 \times$ objective ( 0.9 digital zoom, $1 \mu \mathrm{m} z$-separation). Resulting images were analyzed off-line using Neurolucida for Confocal software (MicroBrightField, Colchester, VT, USA) to determine the expression of GFP, HCN1, 2 or 4 immunolabeling in PV-expressing cells.

\section{Electrophysiology Experiments}

Recording micropipettes were made from borosilicate glass (1.5 mm OD, Harvard Apparatus, Kent, UK) and filled with 
a HEPES based internal solution containing in mM: $124 \mathrm{~K}-$ gluconate, 10 phosphocreatine di tris salt, 10 HEPES, 0.2 EGTA, $4 \mathrm{Mg} 2 \mathrm{ATP}$, and $0.3 \mathrm{Na2GTP}$ ( $\mathrm{pH} 7.3$, adjusted with $\mathrm{KOH}$; Wang et al., 1994; Xu et al., 1997; Hayar et al., 2008). Series resistance $\left(R_{S}\right)$, membrane capacitance, and input resistance $\left(\mathrm{R}_{\mathrm{IN}}\right)$ were assessed based on the response to a hyperpolarizing $5 \mathrm{mV}$ voltage step. These values were monitored throughout each experiment and when $\mathrm{R}_{\mathrm{IN}}$ and/or $\mathrm{R}_{\mathrm{S}}$ changed by more than $20 \%$ or $>25 \mathrm{M} \Omega$, respectively, cells were excluded from the analysis. Recordings were made at room temperature $\left(22-24^{\circ} \mathrm{C}\right)$ and membrane potentials were not corrected for liquid junction potential.

To study APs, a depolarizing step protocol (100 pA increments, $800 \mathrm{~ms}$ duration) was applied to cells in the current clamp recording mode. Rheobase current was calculated as the smallest current step that evoked an AP. The AP generated for each cell at rheobase was used to measure AP threshold, rise time, amplitude, and width. AP threshold was determined on an expanded time scale by identifying the inflection point where membrane potential change exceeded $15 \mathrm{~V} / \mathrm{s}$. AP rise time was measured as $10-90 \%$ of the duration between AP threshold and the maximum positive peak, AP amplitude was the voltage difference between AP threshold and the maximum positive peak, and AP width was the duration of the positive spike at AP threshold. A derivative method was also used to differentiate between monophasic and biphasic repolarization phases on differentiated Rheobase APs. Previous work has shown biphasic repolarization reflects a depolarizing hump that is characteristic of nociceptive DRGs and can be used to identify this class. To test for the presence of $\mathrm{I}_{\mathrm{h}}$, a current clamp protocol delivered several hyperpolarizing steps of increasing amplitude $(-100 \mathrm{pA}$ increments, $800 \mathrm{~ms}$ duration, $-50 \mathrm{mV}$ holding potential). If $\mathrm{I}_{\mathrm{h}}$ was observed, a voltage clamp protocol was applied (10 $\mathrm{mV}$ steps, $800 \mathrm{~ms}$ duration, $-50 \mathrm{mV}$ holding potential) to the maximum amplitude of $-110 \mathrm{mV}$. Current amplitude and activation kinetics were assessed using Axograph $\mathrm{X}$ analysis software.

\section{Pharmacology}

The identity of the hyperpolarization-evoked currents as $\mathrm{I}_{\mathrm{h}}$ current was confirmed by the addition of 4 -(N-EthylN-phenylamino)-1,2 dimethyl-6-(methylamino) pyrimidinium chloride (ZD7288, Sigma-Aldrich), to the bath at a final concentration of $100 \mu \mathrm{M}$. In these experiments, a single $-300 \mathrm{pA}$ step ( $800 \mathrm{~ms}$ every $8.5 \mathrm{~s}$ ) was applied to the cell in the currentclamp. This step was sufficient to monitor the $\mathrm{I}_{\mathrm{h}}$ block during the ZD7288 application. Although some work indicates ZD7288 also affects Na channels (Wu et al., 2012), this off-target effect did not influence the large hyperpolarizing current step responses we assess.

\section{Molecular Experiments}

\section{Cell Collection}

Using DEPC treated solutions, DRGs were removed and dissociated as described above. From the resulting suspension, 200-300 $\mu \mathrm{l}$ was plated on a plastic coverslip. Cells were allowed to settle for 15-20 min before the excess fluid was replaced with fresh HEPES buffer. GFP+ cells were visualized under fluorescent microscopy and collected, via gentle suction, into a glass micropipette (filled with DEPC HEPES) mounted on a micromanipulator. Once 50 cells were collected, they were expelled via positive pressure into a $2 \mathrm{ml}$ Eppendorf tube. This process was repeated to collect $50 \mathrm{GFP}$ - cells.

\section{RNA Extraction and DNase Digestion}

RNA extraction and purification from the 50-cell samples were completed as per the protocol "Cells" included in the RNeasy Micro Handbook (2nd Edition, Qiagen, 2007), using the solutions included in an RNeasy Micro kit (Qiagen Cat No 74004). RNA concentrations were then determined using a Nanodrop-1000 spectrophotometer (ThermoFisher Scientific Inc, Waltham, MA USA). This process provided approximately $10 \mu \mathrm{l}$ of RNA sample to be used for reverse transcription (RT). To eliminate residual genomic DNA contamination, a DNA digestion step was performed at room temperature for 15 min after RNA extraction. In PCR grade microtubes (Scientific Specialties Incorporated, Lodi, CA, USA), $5 \mu l$ of the RNA samples were incubated with $1 \mu$ l DNase and $1 \mu$ l DNase $10 \times$ Buffer (both included in Invitrogen ${ }^{\mathrm{TM}}$ DNase I, Kit I) and $3 \mu$ l Nuclease free water (Qiagen). This process was halted by adding $1 \mu \mathrm{l}$ of EDTA $(25 \mathrm{mM}$, Invitrogen $^{\mathrm{TM}}$ DNase I Kit I) and heating the samples in a thermocycler (Eppendorf, South Pacific) at $65^{\circ} \mathrm{C}$ for $10 \mathrm{~min}$.

\section{Reverse Transcription (RT)}

For RT, a $5 \mu$ l aliquot from each of the DNA-free RNA samples $(\mathrm{GFP}+/-)$ was obtained for cDNA reactions. Oligo dT primers and Deoxynucleotide triphosphates (dNTPs, both from Bioline Pty Ltd.) as well as random hexamers (GeneWorks Pty Ltd, Adelaide, SA Australia) were added to the RT reaction and processed in a thermocycler for $5 \mathrm{~min}$ at $65^{\circ} \mathrm{C}$ before being cooled to $4^{\circ} \mathrm{C}$ and placed on ice for $1 \mathrm{~min}$. Following this, $4 \mu \mathrm{l}$ of $5 \times$ First Strand buffer, $1 \mu \mathrm{l}$ RNase inhibitor, $1 \mu \mathrm{l}$ Dithiothreitol (DTT, all from Bioline Pty Ltd.), as well as 1 $\mu l$ reverse transcriptase (Superscript III, Invitrogen), was added before running in a thermocycler at $50^{\circ} \mathrm{C}$ for 60 mins, then $75^{\circ} \mathrm{C}$ for 15 mins. For quality control, each RT sample was paired with a reverse transcriptase absent sample (called RT+ and RT-, respectively), where the $3 \mu \mathrm{l}$ volume was replaced with Nuclease free water (Qiagen).

\section{Qualitative Polymerase Chain Reaction (qPCR)}

Based on RNA spectrophotometer readings, the cDNA samples were diluted in nuclease-free water to a final concentration of $0.2 \mathrm{ng} / \mu \mathrm{l}$. Forward and reverse 5 prime $\left(5^{\prime}\right)$ primers for the four HCN subunits (Horwitz et al., 2011), GFP (Klein et al., 2000) and $ß$-actin were included (see Table 1). Separate qPCR master mixes were made for each gene to be investigated (GFP, $B$-actin and HCN 1-4). Each master mix contained forward and reverse primers for the target gene at a final concentration of $20 \mu \mathrm{M}$. The SYBR green-based master mix from Bioline was used for all qPCRs. Each qPCR reaction comprised $7 \mu$ l of the master mix, primers, and water, plus $5 \mu \mathrm{l}$ of cDNA sample for 
TABLE 1 | Primer sequence details.

\begin{tabular}{|c|c|c|}
\hline Primer & Sequence & Supplier \\
\hline HCN1 & $\begin{array}{l}\text { Forward-ACATGCTGTGCATT } \\
\text { GGTATGGCG } \\
\text { Reverse-AACAAACATTGCGT } \\
\text { AGCAGGTGGC }\end{array}$ & GeneWorks Pty Ltd \\
\hline HCN2 & $\begin{array}{l}\text { Forward-ACTTCCGCACCG } \\
\text { GCATTGTTATTG } \\
\text { Reverse-TCGATTCCCTTCTT } \\
\text { CACTATGAGG }\end{array}$ & GeneWorks Pty Ltd \\
\hline HCN3 & $\begin{array}{l}\text { Forward-CCTCATCCGCTACA } \\
\text { TACACCAGT } \\
\text { Reverse-GACACAGAGCAA } \\
\text { CATCATTCC }\end{array}$ & GeneWorks Pty Ltd \\
\hline HCN4 & $\begin{array}{l}\text { Forward-GCATGATGCTTCTG } \\
\text { CTGTGTCACT } \\
\text { Reverse-TTCACCATGCCATT } \\
\text { GATGGACACC }\end{array}$ & GeneWorks Pty Ltd \\
\hline Beta Actin & $\begin{array}{l}\text { Forward-ATGGAGGGGAAT } \\
\text { ACAGCCC } \\
\text { Reverse-TTCTTGCAGCTCC } \\
\text { TाCGTT }\end{array}$ & GeneWorks Pty Ltd \\
\hline eGFP & $\begin{array}{l}\text { Forward-ATCATGGCCGAC } \\
\text { AAGCAGAAGAAC } \\
\text { Reverse-GTACAGCTCGTC } \\
\text { CATGCCGAGAGT }\end{array}$ & GeneWorks Pty Ltd \\
\hline
\end{tabular}

a total reaction volume of $12 \mu \mathrm{l}$. All reactions were run on an ABI 7500 Real-Time Thermal Cycler (ThermoFisher Scientific, Australia). After an initial polymerase activation step at $95^{\circ} \mathrm{C}$ for $10 \mathrm{~min}$, there were 40 amplification cycles comprising a $95^{\circ} \mathrm{C}$, $15 \mathrm{~s}$ denaturation step, followed by a $60^{\circ} \mathrm{C} 1 \mathrm{~min}$ annealing and extension step. All samples from a single animal (GFP+ and $\mathrm{GFP}-$ ) were run in triplicate on the same qPCR plate. In addition to the RT+ and RT- samples, water controls were included on all plates, where nuclease-free water was substituted for cDNA.

\section{Analysis}

For the electrophysiological data, statistical analysis was carried out using SPSS v10 (SPSS Inc., Chicago, IL, USA). Following normality checks (Shapiro-Wilks), independent $t$-tests and non-parametric Mann-Whitney tests were applied as appropriate across each measurement. The qPCR analysis was undertaken on paired samples of GFP+ and GFP- cells $(n=50)$. Each sample was tested in triplicate using forward and reverse primers for GFP and HCN 1-4 and the internal control gene $\beta$ actin. Mean cycle threshold (Ct) values were determined for each triplicate (from each animal) and were used to determine $\Delta \mathrm{Ct}$ by subtracting the mean $\mathrm{Ct}$ of the internal control ( $\beta$ actin) from the mean Ct of the target primer (i.e., GFP and HCN 1-4). The resulting $\Delta \mathrm{Ct}$ values were analyzed for normality using a Shapiro-Wilks test. Normality was satisfied in all comparison groups except HCN 3. Thus, a two-tailed paired sample T-test was applied to the $\mathrm{HCN} \mathrm{1,2}$ and 4, while a nonparametric Wilcoxon test was applied to HCN 3 to compare GFP+ and $\mathrm{GFP}-$ groups. $\Delta \mathrm{Ct}$ values were converted to fold-change values between groups for each primer. Statistical significance was set at $p<0.05$. All values are presented in the text as means \pm SEM.

\section{RESULTS}

\section{Co-localization of Green Fluorescent Protein and Endogenous Parvalbumin}

To first confirm reliable and selective GFP expression, DRGs were extracted and immunolabeled for PV and GFP. Co-localization between PV immunoreactive neurons and GFP expression occurred in $100 \%$ of the 645 cells analyzed from PVGFP mice ( $n=3$, two DRGs per mouse). Additionally, we found that there were no instances of cells expressing GFP or PV in isolation (see Figure 1). These data show the PVeGFP transgenic mouse line reliably marks sensory neurons expressing PV.

\section{Electrophysiological Properties}

Whole cell patch clamp recordings were made from isolated cells taken from 21 adult PV-eGFP mice (average yield $=3.1$ recordings per animal). The data (presented herein as GFP+ vs. GFP-) for passive membrane properties are summarized in Figure 2. Input resistance was lower in GFP+ cells when compared with GFP- cells (152.18 \pm 18.34 vs. $388.63 \pm 68.79 \mathrm{M} \Omega, p=0.01, n=35$ and 32, respectively). Series resistance was similar in GFP+ and GFP - cells (12.0 \pm 0.5 vs. $12.4 \pm 0.6 \mathrm{M} \Omega, p=0.64, n=35$ and 32 , respectively, data not shown). Membrane capacitance (32.16 \pm 2.02 vs. $34.47 \pm 2.34 \mathrm{pF}, p=0.46, n=35$ and 32 , respectively) and resting membrane potential $(-42.99 \pm 1.43$ and $-41.14 \pm 2.26 \mathrm{mV}$, $p=0.88, n=35$ and 32 , respectively) were similar in GFP+ and GFP - cells. Cell diameter (29.72 \pm 0.94 vs. $28.08 \pm 0.67$ $\mu \mathrm{m}, p=0.21, n=25$ and 26 , respectively), as measured via a calibrated scale bar, was also similar in both populations.

AP discharge was assessed in response to multiple depolarizing step injections in the recorded cell as shown in Figure 3. The resulting AP discharge was classified as either single (SS) or multiple spiking (MS). All GFP+ cells exhibited the SS discharge profile (25/25 cells), whereas only $70 \%$ (17/24 cells) of the GFP- population exhibited the SS spiking profile. The remaining GFP- cells fired multiple spikes that were a mix of phasic bursting and tonic firing phenotypes. The properties of the first AP generated in response to current injection (rheobase) were also compared between groups. No differences in rheobase current $(325 \pm 25.52$ vs. $388.89 \pm 52.79 \mathrm{pA}, p=0.80, n=28$ and 27 , respectively) or AP peak amplitude $(57.55 \pm 2.76$ vs. $47.64 \pm 4.53 \mathrm{mV}$, $p=0.06, n=28$ and 27 , respectively) were identified between $\mathrm{GFP}+$ and GFP- cells. In contrast, AP threshold occurred at more hyperpolarized potentials $(-16.44 \pm 1.15$ vs. $-1.40 \pm 2.23 \mathrm{mV} p=0.01, n=28$ and 27, respectively); rise time was faster $(0.77 \pm 0.06$ vs. $1.83 \pm 0.19 \mathrm{~ms}, p=0.00$, $n=28$ and 27, respectively); and AP half-width was significantly shorter $(1.15 \pm 0.07$ vs. $2.55 \pm 0.28 \mathrm{~ms}, p=0.00, n=28$ and 27 , respectively) in GFP+ recordings compared with the GFPpopulation. Rheobase AP traces were also differentiated to assess the presence of biphasic repolarization, which has been shown to reflect a depolarizing hump featured in APs from nociceptive afferents (Figure 3C). This assessment showed 

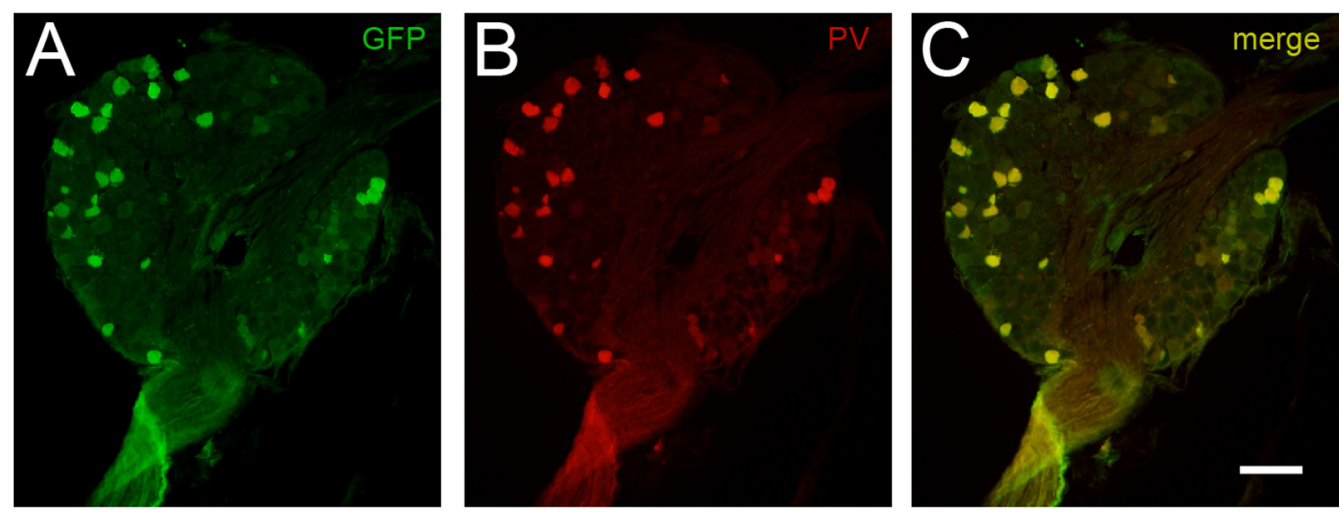

FIGURE 1 | Comparison of GFP-expression and parvalbumin (PV) immunolabeling in dorsal root ganglia (DRG) cells. The fidelity of GFP expression in PV-expressing DRG neurons was tested to confirm the utility of tissue from the PVeGFP transgenic mouse line. Panels (A,B) show a representative DRG section immunolabeled for GFP (green) and PV (red), respectively. Overlaid image (C) shows co-localization (yellow) of GFP and endogenous PV in DRG cells. This analysis showed complete overlap (100\%) in 645 DRG cells examined ( $n=3$ animals). Scale (A-C) $=100 \mu \mathrm{m}$.

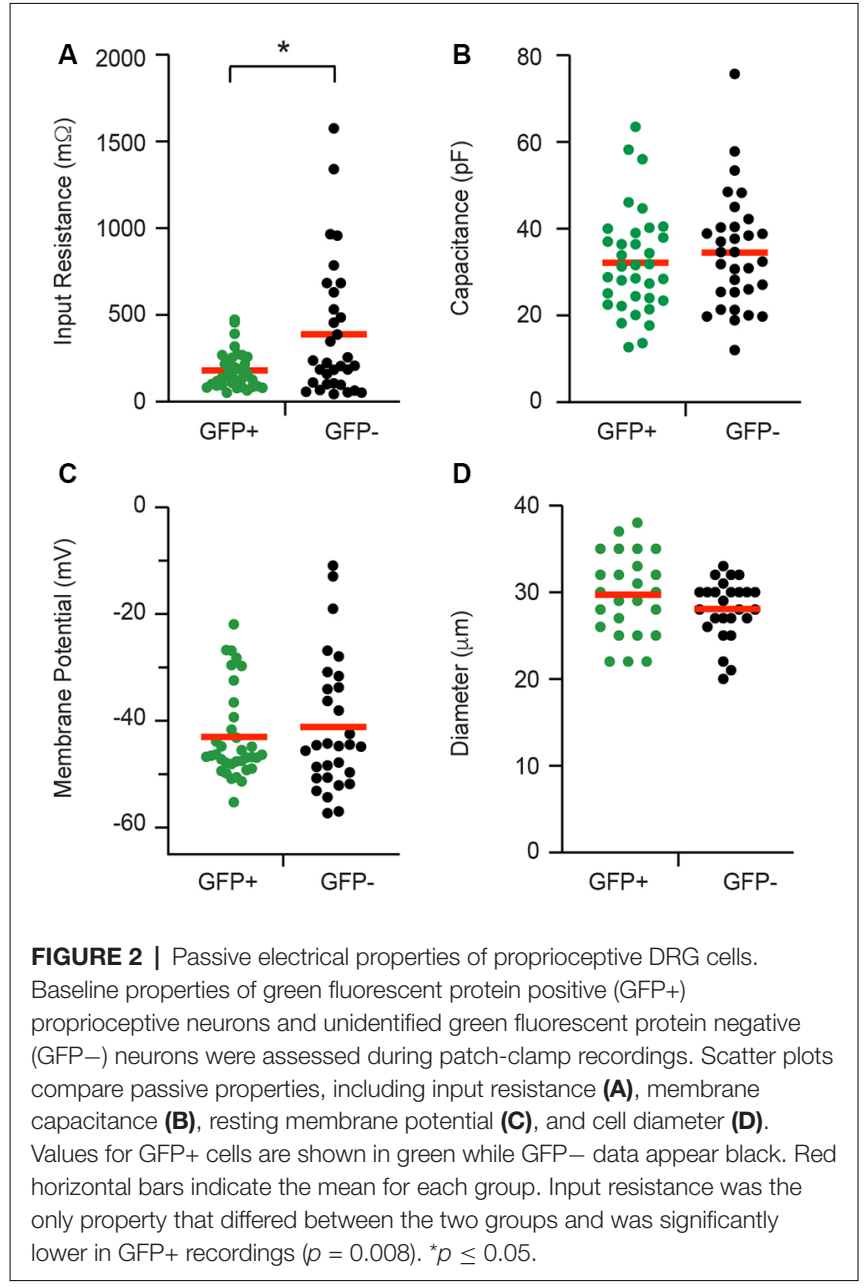

that all GFP+ cells exhibited a monophasic repolarization, whereas 15/24 GFP- cells exhibited biphasic responses (Figure 3D).
During current-clamp recordings hyperpolarizing current step injection responses often featured a "sag" in membrane potential, which then returned towards RMP, consistent with an $\mathrm{I}_{h}$ current (Figures 4A,B). All recordings that assessed this feature confirmed GFP+ cells exhibited $\mathrm{I}_{\mathrm{h}}$-like currents (18/18 recordings), whereas these currents were only detected in $11 \%(2 / 17)$ of the GFP - cells. The identity of this current was verified in a subset of recordings by testing ZD7288 (100 $\mu \mathrm{M}$ ) sensitivity, a commonly used blocker of $\mathrm{I}_{\mathrm{h}}$ (Figure $4 \mathrm{C}$, $n=3)$. $\mathrm{I}_{\mathrm{h}}$ currents were also studying in voltage-clamp using a protocol that stepped membrane potential from $-50 \mathrm{mV}$ to more hyperpolarized potentials in $10 \mathrm{mV}$ increments (Figure 4D). The average $I_{h}$ amplitude for each voltage step was calculated as the difference between values immediately after the onset and conclusion of seven hyperpolarizing steps $(-50$ to $-110 \mathrm{mV})$. The box-whisker plots (Figure 4E) show average $I_{h}$ amplitude did not differ for the first two voltage steps (to -50 and $-60 \mathrm{mV}$ ) in GFP+ and GFP- cells ( $p=0.70$ and 0.16 , respectively). However, $\mathrm{I}_{\mathrm{h}}$ currents were much larger in GFP+ cells for the steps between -70 and $-110 \mathrm{mV}$. This is indicative of the presence of substantial $\mathrm{I}_{\mathrm{h}}$ in GFP+ cells $(-70 \mathrm{mV} p=0.001,-80 \mathrm{mV}$ $p=0.002,-90 \mathrm{mV} p=0.004,-100 \mathrm{mV} p=0.003$ and $-110 \mathrm{mV}$ $p=0.003)$.

The activation rate of $\mathrm{I}_{\mathrm{h}}$ was also assessed by fitting an exponential over 10\%-90\% of the maximum current amplitude (i.e., the $-110 \mathrm{mV}$ step) for GFP+ and GFP- cells (Figure 4D). The resulting $\mathrm{I}_{\mathrm{h}}$ activation time constant values varied markedly for GFP+ cells $(0.08-0.83 \mathrm{~s})$. Values for the two GFP- cells that expressed $\mathrm{I}_{\mathrm{h}}$ had similar activation rates $(0.27$ and $0.24 \mathrm{~s})$ and fell within the range expressed by the GFP+ cells.

\section{Gene Expression: qPCR Ct Analysis for HCN Channel Subunits}

We next examined the mRNA expression levels of $\mathrm{HCN}$ 1-4 subunits to gain insight into the molecular determinants of the $\mathrm{I}_{\mathrm{h}}$ currents and activation rates reported above (Figure $4 \mathrm{~F}$ ). 

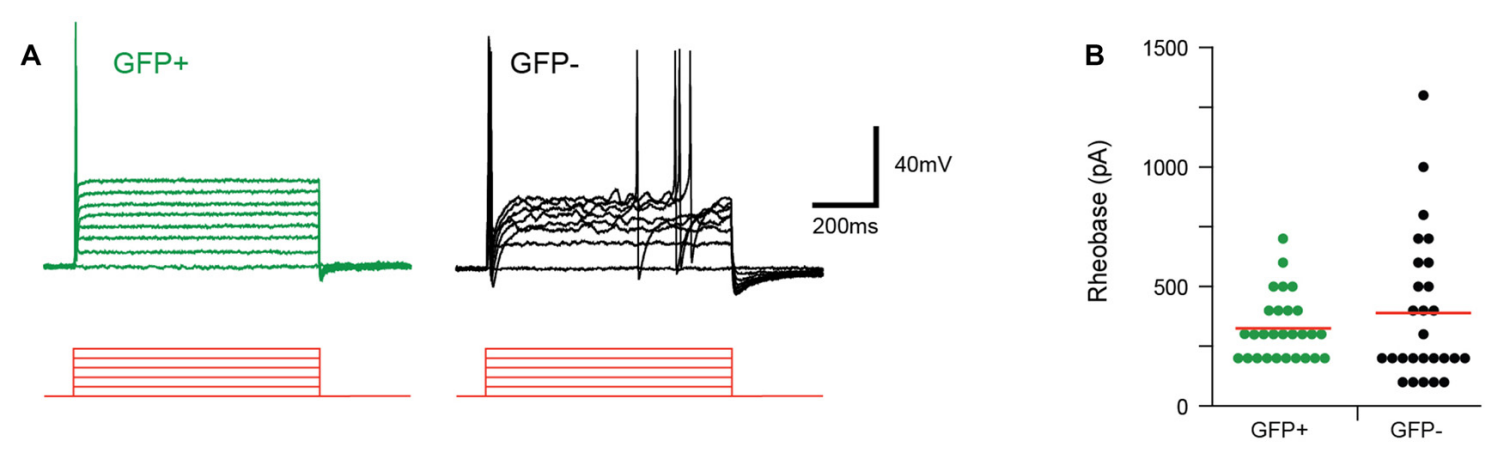

c

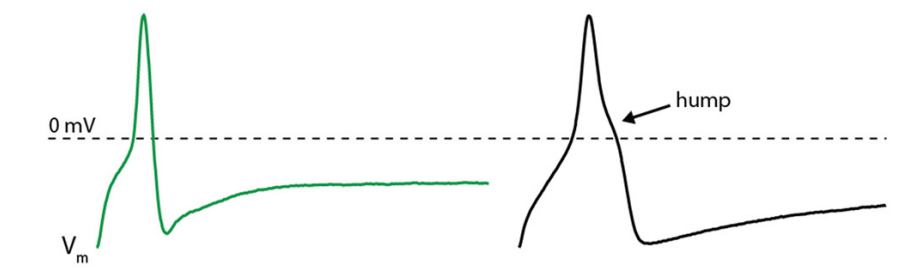

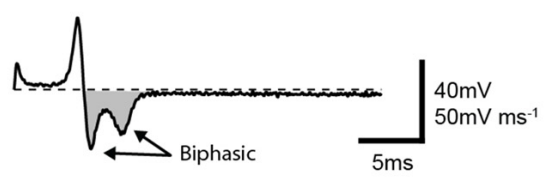

D
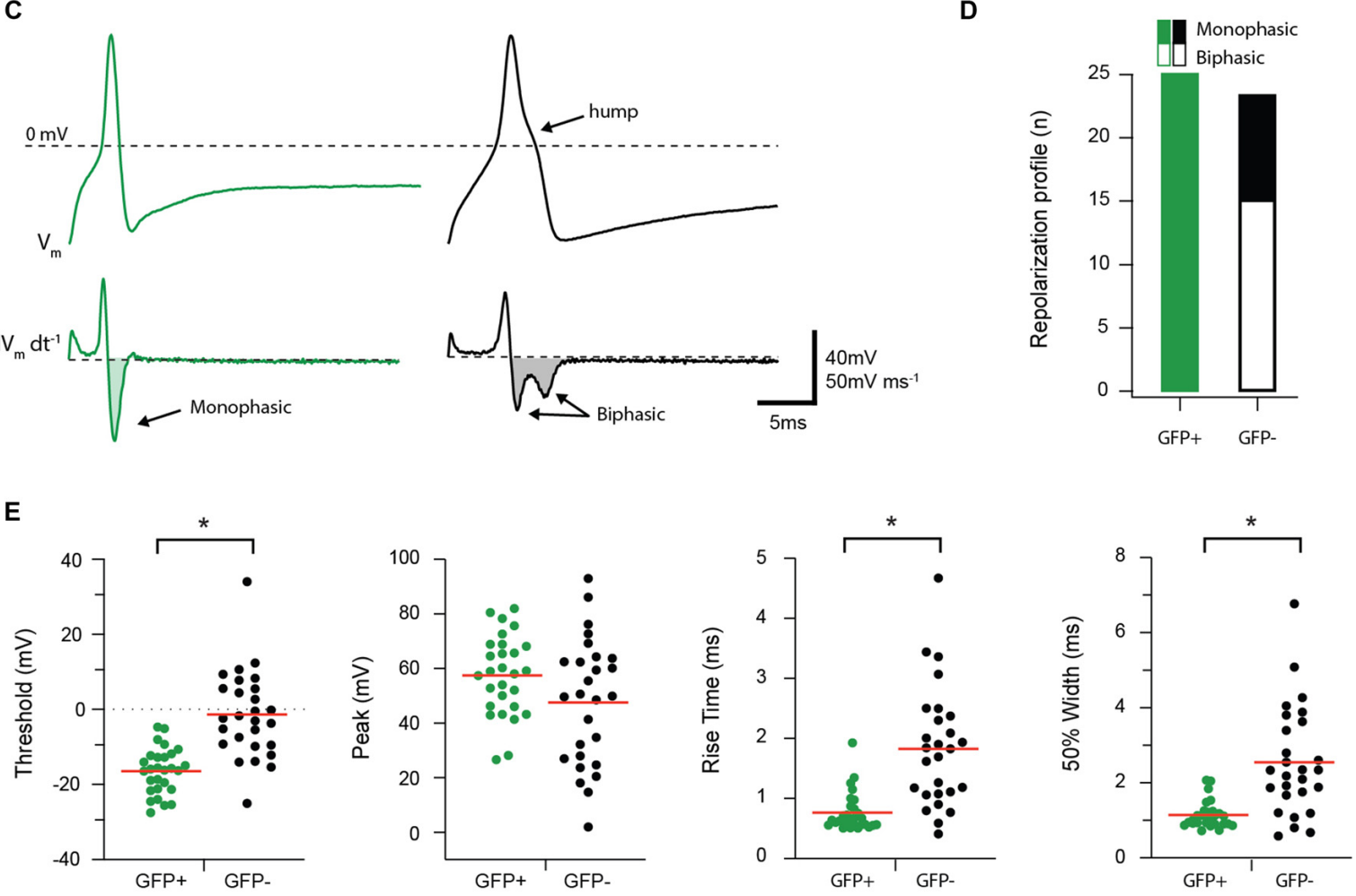

FIGURE 3 | Discharge and action potential (AP) properties of proprioceptive DRG cells. Two types of AP discharge were observed in DRG neurons during step current injections (100 pA increments, 800 ms duration, red traces). (A) Overlaid traces show a typical response from GFP+ and GFP- cells, contrasting a single spike response at the onset of current injection in GFP+ cells with multi-spiking responses observed in some GFP- recordings (7/24). (B) Scatter plot shows group data comparing Rheobase in GFP+ (green circles) and GFP- (black circles) cells. While group means (red lines) are similar for both groups, the spread, and range of data in GFP - cells is greater. (C) Upper traces show rheobase APs from a GFP+ (green trace) and GFP - cell (black trace) on an expanded time scale. Note while APs exhibit a similar amplitude, the time courses are distinct, with GFP+ cells exhibiting faster APs and a distinct hump appearing on the repolarization phase in the GFP - trace. Lower traces are differentiated AP data (from above) clearly identifying the distinct repolarization phases of GFP+ and GFP- cells as monophasic and biphasic waveforms, respectively. (D) Bar graph summarizes relative incidence of cells exhibiting monophasic (filled bar) and biphasic (open bar) differentiated waveforms. All GFP+ cells exhibited monophasic waveforms, whereas more than half the GFP - cells exhibited biphasic responses (15/24). (E) Scatter plots show group data comparing AP properties in GFP+ (green circles) and GFP - (black circles) cells. AP height was similar in GFP+ and GFP - cells, but AP threshold, rise time, and half-width differed in the two cell types, with faster kinetics and more hyperpolarized thresholds in the GFP+ sample $(p<0.05) .{ }^{*} p \leq 0.05$.

A qPCR analysis was first undertaken on paired samples of pooled GFP+ vs. GFP - cells for specific GFP primers to confirm our isolation procedures faithfully captured populations of GFP+ and GFP - cells (Figure 5A). Mean Ct values show there was a large difference in $\triangle \mathrm{Ct}$ values for the GFP+ and GFP - sample $(-0.11 \pm 0.25$ vs. $6.19 \pm 0.15, p>0.01)$. When expressed as a fold difference, there was $>90$ times more GFP expression in our GFP+ vs. GFP- sample. This confirmed our procedures provided a highly enriched sample of PV positive (GFP-expressing putative proprioceptive) cells for subsequent analysis of $\mathrm{HCN}$ subunit expression.

Regarding HCN subunit mRNA expression, significantly higher levels of $\mathrm{HCN} 1,2$ and 4 were detected in the GFP+ vs. GFP- sample, reflected in lower $\Delta \mathrm{Ct}$ values (Figure 5B) 


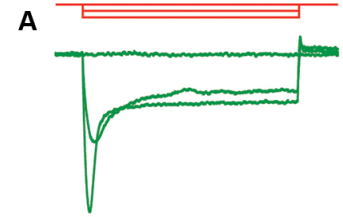

C

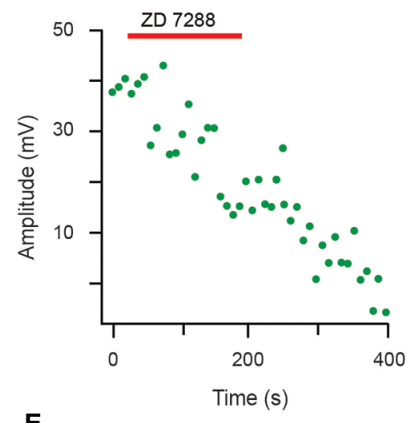

E

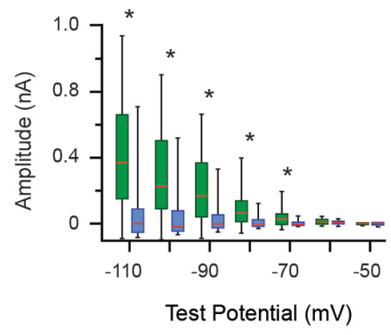

B

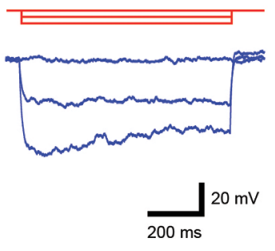

D

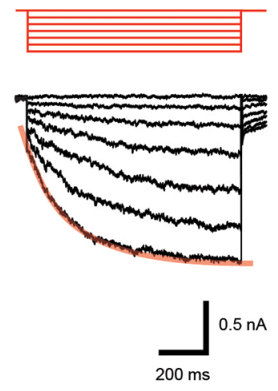

$\mathbf{F}$

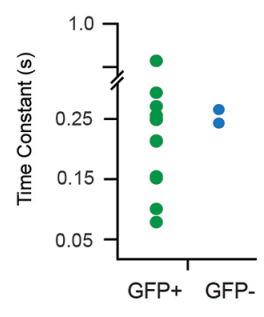

FIGURE 4 | Properties of hyperpolarization-activated currents $\left(l_{h}\right)$ in proprioceptive DRG cells. (A,B) Overlaid traces showing current-clamp recordings from isolated GFP+ and GFP- DRG neurons during hyperpolarizing current injection (3 steps, $100 \mathrm{pA}$ increments, $1 \mathrm{~s}$ duration, red traces). All GFP+ cells exhibited a prominent sag characterized by a rapid return towards resting membrane potential that became more prominent as hyperpolarized step injection amplitude increased (A). This profile is associated with a hyperpolarization activated current, termed $\mathrm{l}_{\mathrm{h}}$. In contrast, few GFP - cells exhibited evidence of the $\ln _{h}$ current and when present it was minimal (B, sag less prominent). (C) Bath application of an antagonist (ZD7288, $100 \mu \mathrm{M}$ ) was used to confirm the identity of $\mathrm{I}_{\mathrm{h}}$ in current-clamp mode. Peak $\mathrm{h}$ voltage amplitude, measured every $8.5 \mathrm{~s}$ in response to a 300 pA hyperpolarizing current step was sensitive to the addition of ZD7288 $(100 \mu \mathrm{M})$, which abolished $\mathrm{I}_{\mathrm{h}}$ responses. (D) Overlaid traces show $\mathrm{I}_{\mathrm{h}}$ currents recorded from a GFP+ cell during a voltage clamp protocol (-10 mV steps, holding potential $-50 \mathrm{mV}$, red traces). These responses feature a prominent voltage-activated current that becomes more pronounced as hyperpolarization is increased. Note red line shows an exponential fit to the $I_{h}$ activation profile during the largest hyperpolarizing step. (E) Box and whisker plot shows group data comparing $\mathrm{l}_{\mathrm{h}}$ amplitude in GFP+ (green) and GFP(blue) cells from the hyperpolarizing step responses (shown in $\mathbf{D})$. I $\mathrm{h}$ amplitude is minimal until steps reach $-70 \mathrm{mV}$ before hyperpolarization $\mathrm{I}_{\mathrm{h}}$ amplitude begins to increase substantially in GFP+ neurons $(p<0.005)$. (F) An exponential was fit to the largest $\ln$ current trace (i.e., $-110 \mathrm{mV}$ step, overlaid red line) providing a time constant (or, activation rate) for $\mathrm{ln}$ in GFP+ (green) and the two GFP - cells (blue). Activation rates varied markedly for GFP+ cells while the two GFP - cells had similar values that fell within the range of GFP+ activation rates. ${ }^{*} p \leq 0.05$.

and equating to 1,5-, 3-, and 3.5-fold differences, respectively. In contrast, HCN 3 was the only subunit to show lower expression in the GFP+ vs. GFP - sample $(\Delta \mathrm{Ct}=8.7 \pm 0.3$ vs. $7.7 \pm 0.1$, $p=0.03$; Figure 5B), representing a 0.5 -fold difference. Within each group, HCN 2 was the most highly expressed subunit in GFP+ and GFP - samples. For GFP+ cells, HCN 2 expression was highest, followed by $\mathrm{HCN} 1$ then $\mathrm{HCN} 4(\Delta \mathrm{Ct}=2.96 \pm 0.16$ vs. $5.49 \pm 0.150$ vs. $7.35 \pm 0.15)$.

\section{HCN Channel Subunit Expression in PV DRG Neurons}

To assess the impact of the above findings at a protein level, DRGs from wildtype tissue were immunolabeled for PV and HCN subunit expression. PV positive DRG cells were identified by immunolabeling in the cytoplasm of subpopulations of DRG neurons, whereas that for HCN1 and HCN2 was confined to membranes of cell bodies and axons in restricted subsets of cells (Figures 6A,B). In contrast, immunolabeling for HCN4 was expressed in the cytoplasm, and therefore deemed nonspecific. In earlier pilot experiments using tissue from PVeGFP mice, HCN2 and HCN4 immunolabeling were confined to membranes and axons of GFP labeled DRG neurons, but not analyzed (Figures 6C,D). Nevertheless, this observation confirms some PV positive DRG neurons also express $\mathrm{HCN} 4$ in their membranes, albeit without formal quantification. Regarding HCN1 and HCN2 subunit labeling that could be analyzed, less than half of PV-IR neurons expressed immunolabeling for HCN1 (mean 43.8\% \pm 8.8; 15/34 PV cells; $n=2$ animals), whereas HCN2 was expressed in half than half the PV-IR sample (mean $65.3 \% \pm 11.0 ; 48 / 75$ PV cells; $n=3$ ). These observations confirm that the HCN subunit mRNA identified in qPCR experiments does translate to functional protein in PV DRG cells, and the relative incidence of HCN1 and HCN2 subunit expression among PV cells also mirrors the mRNA levels detected in this population.

\section{DISCUSSION}

This study used targeted patch-clamp electrophysiology and molecular analysis of HCN channel subtypes to compare the properties of putative proprioceptive neurons $(\mathrm{GFP}+$ ) with a group of non-proprioceptive "other" sensory populations (GFP-). Our main electrophysiology findings are that GFP+ and GFP- neurons differed in their active and $\mathrm{I}_{\mathrm{h}}$ properties. Molecular analysis, supported by immunolabeling, showed expression of $\mathrm{HCN} 1,2$ and 4 subunits were higher in GFP+ neurons. In contrast, HCN 3 subunits, though expressed at low levels, were more highly expressed in GFP- cells. Below, we discuss the caveats associated with our experiments and our main findings in terms of their relevance to proprioceptive signaling.

During depolarizing current step injection, GFP+ neurons always exhibited a single spike phenotype whereas GFPneurons showed a mix of single and MS (Figure 3). The phasic firing and strong adaptation in GFP+ neurons are consistent with the in vivo responses of sensory neurons that innervate Pacinian corpuscles and muscle spindles (Lawson, 2005). Both receptor types are classed as low threshold mechanoreceptors, have fast conduction velocities, and are best suited to signaling rapid changes in pressure and muscle length, respectively. Such 

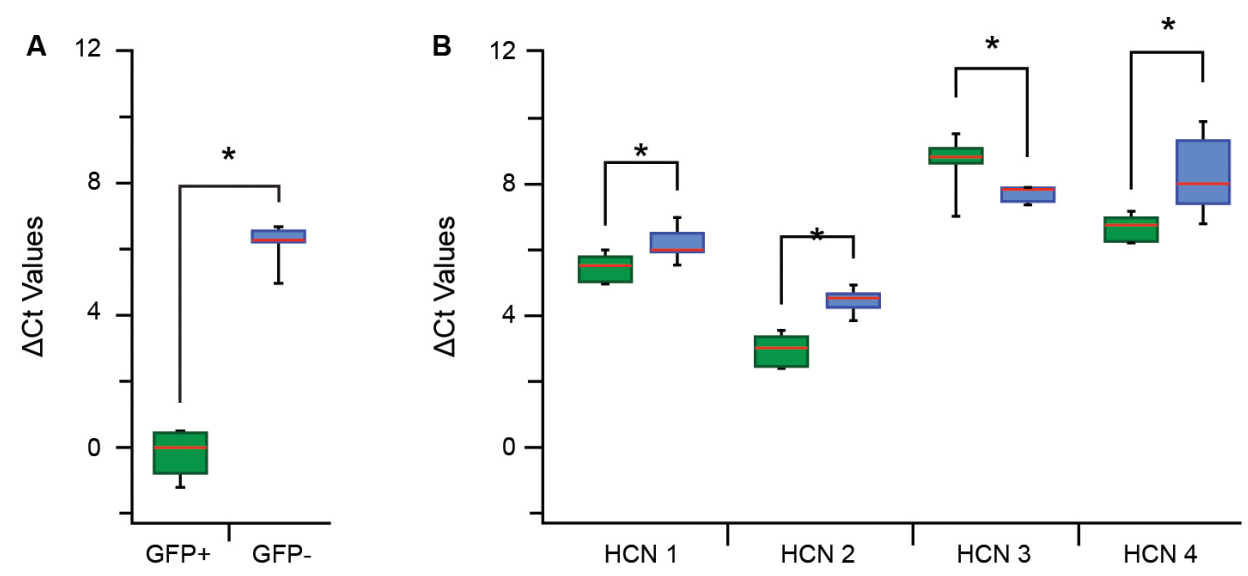

FIGURE 5 | Quantitative polymerase chain reaction (qPCR) $\triangle \mathrm{Ct}$ analysis for hyperpolarization-activated cyclic nucleotide-gated channel (HCN channel) subunits in proprioceptive DRG cells. (A) Box and whisker plot show group data comparing $\Delta$ Ct for GFP expression in GFP+ (green) and GFP- (blue) samples (normalized to $\beta$ actin expression). The low GFP $\Delta$ Ct in GFP+, but not GFP-, confirm high expression in this sample and the reliability of this sampling approach. (B) Box whisker plots plot shows group data comparing $\triangle$ Ct values for HCN1-4 in GFP+ (green) and GFP- (blue) samples. The expression of all HCN subunits was significantly different between GFP+ and GFP - groups (where ${ }^{*} p<0.05$ ). HCN 2 had the greatest overall expression in both samples whilst HCN 3 and 4 were both expressed at much lower levels. Expression levels were highest for HCN 2, then HCN 1 and HCN 4 in the GFP+ sample and these values all exceeded corresponding values in the GFP - samples. In contrast, HCN 3 expression was lower in the GFP+ sample vs. GFP - cells.
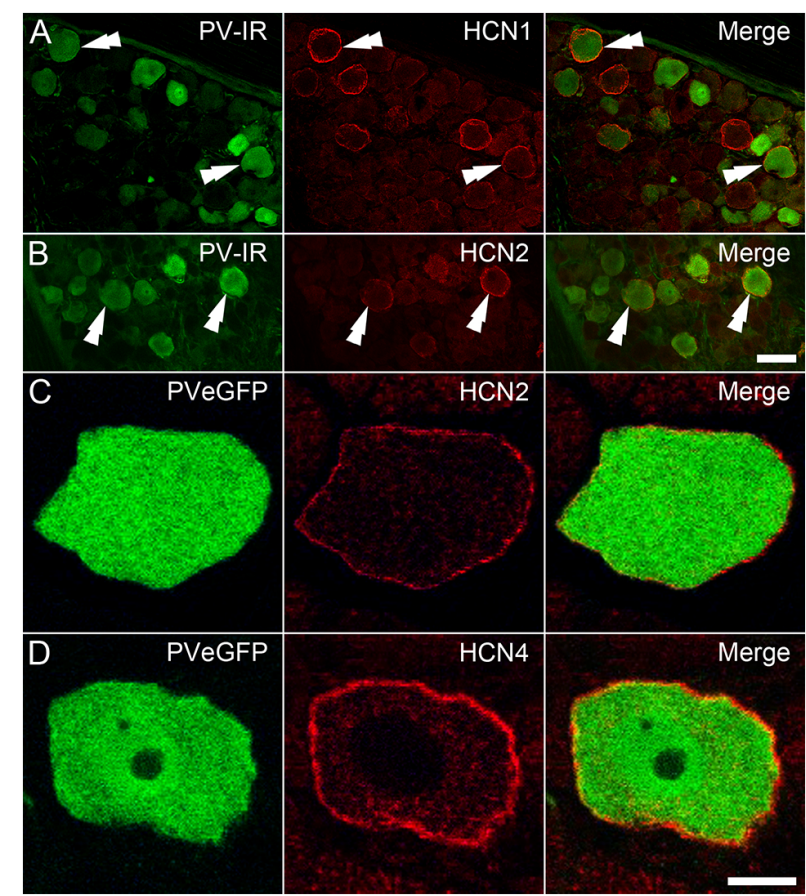

FIGURE 6 | Immunohistochemical localization of HCN subunits in PV-expressing DRG neurons. (A,B) PV-IR DRG neurons (green) in wild-type mice were shown to express both $\mathrm{HCN} 1$ (A; red) and HCN2 (B; red), with examples denoted by double arrowheads. (C,D) In DRGs from PVeGFP mice, GFP-expressing cells (green) showed immunolabeling for both HCN2 (C; red) and HCN4 (D; red). Immunolabeling for each of the HCN subunits was restricted to the cell membrane. Scale Bars $(\mu \mathrm{m}):(\mathbf{A}, \mathbf{B})=50 ;(\mathbf{C}, \mathbf{D})=10$.

signaling would require AP discharge at the onset or offset of a stimulus. Their phasic discharge (Figure 3A), however, is at odds with the known ability of muscle spindle afferents to support high-frequency firing, especially at the onset and cessation of muscle lengthening.

This above discrepancy presumably relates to a number of factors. First, the use of a long square step stimulus does not reflect the way neurons are excited in vivo with different stimulus profiles shown to produce different responses depending on other neuronal populations (Graham et al., 2004). Second, our recordings were made from the soma of isolated sensory neurons vs. an intact preparation. In vivo, AP generation occurs in peripheral terminals and is conducted in a centrallyprojecting axon that is linked to the soma of sensory neurons. The excitability of the terminal and axon of proprioceptive fibers, missing in our preparation, maybe more important for determining the firing pattern. Nevertheless, reduced somatic DRG preparations continue to be a useful approach to assay the proteins and channels expressed by different afferent types. Finally, there is evidence that neurons can undergo changes in reduced or isolated preparations that potentially alter the suite of ion channels that support AP generation and/or repetitive discharge (Turrigiano et al., 1994; Hayar et al., 2008; Werner et al., 2012). Future experiments that deliver short depolarizing steps at high frequency, ramps, and stimuli with other profiles would allow exploration of the capacity of GFP+ neurons to support firing modes and frequencies observed in vivo. In the future, it may also be possible to record directly from the peripheral terminals of GFP- labeled proprioceptors. These would be heroic experiments, however, such recordings have been made from the terminals of peripheral sensory nerves in the cornea (Carr et al., 2009).

In addition to the above differences in patterns of discharge, there were also marked differences in individual AP characteristics between the two groups of neurons in our study. APs in GFP+ neurons had faster kinetics, based on AP rise time and half-width (Figure 3C). This finding is consistent with 
data from numerous studies showing large-diameter neurons (like the proprioceptive population) generate narrow APs and respond to much lower stimulation intensities than other DRG cell types (Fang et al., 2005). These properties are also consistent with a role in proprioceptive signaling, where fast and repetitive AP generation is required in response to changes in muscle length (muscle spindles) and/or force (Golgi tendon organs). Similarly, the broader APs in GFP- neurons match the function of high threshold receptors, such as nociceptors, recorded from intact DRG neurons in vivo (Djouhri et al., 1998).

Our assessment of $\mathrm{I}_{\mathrm{h}}$ showed this current to be present in all GFP+ neurons vs. only $\sim 10 \%$ of GFP - neurons. This is consistent with early work which showed significant $I_{h}$ in most large sensory neurons (putative proprioceptors; Scroggs et al., 1994). It also fits with the role hyperpolarizationactivated cationic currents play in high-frequency AP discharge, as occurs in the spindle and GTO afferents (Moosmang et al., 2001; Stevens et al., 2001; Notomi and Shigemoto, 2004; Baruscotti et al., 2005). As multiple HCN channel subunits exist and shape the properties of $I_{h}$ currents, we investigated both amplitude and activation rates of this current (based on fitting exponentials to current onset; Figure 4D). GFP+ neurons exhibited a range of $I_{h}$ amplitudes (Figure 4E) and activation rates (Figure $\mathbf{4 F}$ ), consistent with the expression of different HCN channels/subunits (Acosta et al., 2012; Hughes et al., 2013). Molecular analysis showed all four HCN subunits could be detected in isolated sensory neurons (both GFP+ and GFP- neurons; Figure 5). However, expression profiles were distinct between the GFP+ and GFP - samples. Specifically, HCN 2, 1, and 4 expressions (listed in descending levels based on $\Delta \mathrm{Ct}$ values; Figure $5 \mathbf{B}$ ) were higher in $\mathrm{GFP}+$ vs. GFP- neurons. Alternatively, HCN 3 expression was higher in the GFP- population. Recent data on $\mathrm{HCN} 3$ subunits (Lainez et al., 2019) suggest the expression of HCN 3 in the GFP- population is not important for (small) c-fiber afferents, rather it plays a role in setting excitability in mediumsized neurons that conduct in the $\delta$ and $A \beta$ range (i.e., not muscle spindle and GTO afferents; Lawson, 2002). This finding marries well with the similar cell diameters of GFP and GFP - neurons in our sample. It also suggests or recordings in GFP - neurons may have been biased towards the larger $\delta$ and A $\beta$ DRG cell types, as opposed to the much smaller c-fiber cell population. In contrast, HCN 2 and 1 were highly expressed in GFP+ neurons These observations were also validated at the protein level, with immunolabeling for HCN1, 2, and 4 resolved in PV positive DRG cells. Furthermore, the proportion of PV DRG cells expressing HCN 1 and 2 mirrored mRNA levels and suggested a degree of heterogeneity in subunit expression among proprioceptive afferents identified by PV expression.

Expression patterns favoring $\mathrm{HCN} 1$ and 2 subunits also agree with functional data indicating these subunits exhibit the fastest activation rates of the four $\mathrm{HCN}$ isoforms (Jiang et al., 2008), correlating with the fast $I_{h}$ activation times we recorded in many GFP+ neurons (Figure 4F). This also fits with the high in vivo discharge rates recorded in proprioceptors because fast $\mathrm{HCN}$ channel activation rates elevate resting potential and AP firing frequency (Pape and McCormick, 1989; Pape, 1996; Ludwig et al., 2003; Nolan et al., 2003; Chan et al., 2004; Momin et al., 2008). The higher levels of $\mathrm{HCN} 4$ in GFP+ neurons (vs. GFP- neurons) also match a proposed association between these subunits with high discharge rates (Hughes et al., 2013).

Of course, our examination of the contribution of $\mathrm{I}_{\mathrm{h}}$ and $\mathrm{HCN}$ subunits to GFP+ and GFP- neuron function comes with several caveats. First, we could not determine if the peripheral axon of GFP+ neurons was in fact connected to a proprioceptor (muscle spindle or GTO) due to the dissociated nature of the preparation employed here. This limitation could be addressed in future experiments by making recordings from an ex vivo preparation consisting of a DRG-peripheral nerve-peripheral organ. Such preparations were originally developed to study sensory neurons connected to tactile and nociceptive afferents in the skin (Woodbury et al., 2001). More recently an attached ex vivo muscle preparation was used to study nociceptors in the muscle (Jankowski et al., 2013). The use of an ex vivo muscle preparation in combination with stimuli that selectively activate muscle spindles or GTOs (e.g., ramped muscle stretch) and targeted recording from neurons in DRGs from the PVGFP mouse could address this issue. Achieving visualized high-resolution patch-clamp recordings from GFP+ neurons would also necessitate gentle treatment of DRGs with enzymes that loosen connective tissue and allow for patch pipette access as successfully employed in other ganglia (Yawo, 1989).

A second limitation relates to the population contrasted against the GFP+ proprioceptive neurons, which was a mixed population selected at random, presumably including recordings from a range of afferent types. This would have limited our ability to resolve distinct proprioceptive properties from a mixed control sample. Testing the responsiveness of control (GFP-) recordings to modality-specific agonists such as capsaicin, icilin, menthol, chloroquine, or temperature changes could be used to further dissect this population. Despite this, our analysis of the falling phase of APs did detect biphasic repolarization in many GFP - cells, confirming a depolarization hump associated with nociceptive afferents. Given the similarity of soma size between samples, these are more likely to represent $\delta$ than c-fiber nociceptors. Finally, our examination of the HCN subunit expression was undertaken on populations of pooled cells. Thus, the higher expression could reflect elevated expression across one sample or very high expression in a subset of cells. Our immunolabeling data goes some way to addressing this issue, showing that only subsets of PV cells express HCN1 and 2 ( $\sim 45 \%$ vs. $65 \%$, respectively), supporting heterogeneity within the PV population. This could be further explored by characterizing $\mathrm{I}_{\mathrm{h}}$ properties in single dissociated neurons (GFP+ and GFP-) and subsequent single-cell qPCR analysis for HCN expression. These data would also speak to our conclusion that a range of $\mathrm{I}_{\mathrm{h}}$ amplitudes and activation rates (Figure 4) implies distinct proprioceptive types can be differentiated within GFP+ neurons, based on their $\mathrm{HCN}$ channel profiles. 
In summary, this study was motivated by the notion that distinct properties in a sensory neuron population are likely to impart modality-specific function and as such, may represent targets to alter function in that neuron population. This strategy's value has been highlighted in the successful targeting of sensory neurons involved in nociception and pain (Haberberger et al., 2019). We asked what properties might distinguish proprioceptive neurons from other afferents because a better understanding of these features will be relevant to the well-known age-related decline in proprioceptive function and the increased incidence of falls (Greaves et al., 1991; Kim et al., 2007; Rosant et al., 2007; Wingert et al., 2014). Our analysis of proprioceptive neurons, identified by PV expression, show they indeed have a range of different properties to putative non-proprioceptive neurons. However, the proprioceptive neuron population was not homogeneous, at least based on the expression of $\mathrm{HCN}$ channel subtypes. Notwithstanding these limitations, our study provides a foundation for future studies on the excitability of proprioceptive afferents and how they change with age and/or under sensorimotor pathologies.

\section{DATA AVAILABILITY STATEMENT}

All datasets generated for this study are included in the article.

\section{REFERENCES}

Acar, F., Miller, J., Golshani, K. J., Israel, Z. H., McCartney, S., and Burchiel, K. J. (2008). Pain relief after cervical ganglionectomy (C2 and C3) for the treatment of medically intractable occipital neuralgia. Stereotact. Funct. Neurosurg. 86, 106-112. doi: 10.1159/000113872

Acosta, C., McMullan, S., Djouhri, L., Gao, L., Watkins, R., Berry, C., et al. (2012). HCN1 and HCN2 in Rat DRG neurons: levels in nociceptors and non-nociceptors, NT3-dependence and influence of CFA-induced skin inflammation on HCN2 and NT3 expression. PLoS One 7:e50442. doi: 10.1371/journal.pone.0050442

Arber, S., Ladle, D. R., Lin, J. H., Frank, E., and Jessell, T. M. (2000). ETS gene Er81 controls the formation of functional connections between group Ia sensory afferents and motor neurons. Cell 101, 485-498. doi: 10.1016/s00928674(00)80859-4

Baruscotti, M., Bucchi, A., and Difrancesco, D. (2005). Physiology and pharmacology of the cardiac pacemaker ("funny") current. Pharmacol. Ther. 107, 59-79. doi: 10.1016/j.pharmthera.2005.01.005

Berta, T., Qadri, Y., Tan, P. H., and Ji, R. R. (2017). Targeting dorsal root ganglia and primary sensory neurons for the treatment of chronic pain. Expert Opin. Ther. Targets 21, 695-703. doi: 10.1080/14728222.2017.1328057

Carr, R. W., Pianova, S., McKemy, D. D., and Brock, J. A. (2009). Action potential initiation in the peripheral terminals of cold-sensitive neurones innervating the guinea-pig cornea. J. Physiol. 587, 1249-1264. doi: 10.1113/jphysiol.2008. 167023

Celio, M. R. (1990). Calbindin D-28k and parvalbumin in the rat nervous system. Neuroscience 35, 375-475. doi: 10.1016/0306-4522(90)90091-h

Chan, C. S., Shigemoto, R., Mercer, J. N., and Surmeier, D. J. (2004). HCN2 and HCN1 channels govern the regularity of autonomous pacemaking and synaptic resetting in globus pallidus neurons. J. Neurosci. 24, 9921-9932. doi: 10.1523/JNEUROSCI.2162-04.2004

Deer, T. R., Grigsby, E., Weiner, R. L., Wilcosky, B., and Kramer, J. M. (2013). A prospective study of dorsal root ganglion stimulation for the relief of

\section{ETHICS STATEMENT}

All experimental procedures performed at the University of Newcastle were approved by The University of Newcastle Animal Care and Ethics Committee under Section 25 of the NSW Animal Research Act, 1985. All experimental procedures performed at the University of Glasgow were conducted in accordance with the European Community directive 86/609/EEC and UK Animals (Scientific Procedures) Act 1986.

\section{AUTHOR CONTRIBUTIONS}

JM, RC, PJ, DH, DS, and BG conceived and designed the research study. JM, OD, and $\mathrm{KB}$ conducted experiments and acquired data. JM, TB, JI, RC, OD, KB, and BG analyzed data. JM, TB, RC, $\mathrm{DH}$, and $\mathrm{BG}$ wrote the manuscript. All authors edited the final version of the manuscript.

\section{FUNDING}

This work was funded by the National Health and Medical Research Council (NHMRC) of Australia (Grants 631000, 1043933, 1144638, and 1184974 to BG and RC), the Biotechnology and Biological Sciences Research Council (BB/J000620/1, BB/P007996/1 to DH) and the Hunter Medical Research Institute (Glenn Moss grant to BG).

chronic pain. Neuromodulation 16, 67-71; discussion 71-62. doi: 10.1111/ ner. 12013

de Louw, A. J., Vles, H. S., Freling, G., Herpers, M. J., Arends, J. W., and Kleef, M. (2001). The morphological effects of a radio frequency lesion adjacent to the dorsal root ganglion (RF-DRG) - an experimental study in the goat. Eur. J. Pain 5, 169-174. doi: 10.1053/eujp.2001.0228

Delhaye, B. P., Long, K. H., and Bensmaia, S. J. (2018). Neural basis of touch and proprioception in primate cortex. Compr. Physiol. 8, 1575-1602. doi: 10.1002/cphy.c170033

de Nooij, J. C., Doobar, S., and Jessell, T. M. (2013). Etv1 inactivation reveals proprioceptor subclasses that reflect the level of NT3 expression in muscle targets. Neuron 77, 1055-1068. doi: 10.1016/j.neuron.2013.01.015

Dini, L., Del Lungo, M., Resta, F., Melchiorre, M., Spinelli, V., Di Cesare Mannelli, L., et al. (2018). Selective blockade of HCN1/HCN2 channels as a potential pharmacological strategy against pain. Front. Pharmacol. 9:1252. doi: 10.3389/fphar.2018.01252

Djouhri, L., Bleazard, L., and Lawson, S. N. (1998). Association of somatic action potential shape with sensory receptive properties in guinea-pig dorsal root ganglion neurones. J. Physiol. 513, 857-872. doi: 10.1111/j.1469-7793.1998. 857ba.x

Doan, T. N., and Kunze, D. L. (1999). Contribution of the hyperpolarizationactivated current to the resting membrane potential of rat nodose sensory neurons. J. Physiol. 514, 125-138. doi: 10.1111/j.1469-7793.1999.125af.x

Ernfors, P., Lee, K. F., Kucera, J., and Jaenisch, R. (1994). Lack of neurotrophin-3 leads to deficiencies in the peripheral nervous system and loss of limb proprioceptive afferents. Cell 77, 503-512. doi: 10.1016/0092-8674(94) 90213-5

Fang, X., McMullan, S., Lawson, S. N., and Djouhri, L. (2005). Electrophysiological differences between nociceptive and non-nociceptive dorsal root ganglion neurones in the rat in vivo. J. Physiol. 565, 927-943. doi: 10.1113/jphysiol.2005. 086199

Gao, L. L., McMullan, S., Djouhri, L., Acosta, C., Harper, A. A., and Lawson, S. N. (2012). Expression and properties of hyperpolarization-activated current in rat 
dorsal root ganglion neurons with known sensory function. J. Physiol. 590, 4691-4705. doi: 10.1113/jphysiol.2012.238485

Gradwell, M. A., Boyle, K. A., Callister, R. J., Hughes, D. I., and Graham, B. A. (2017). Heteromeric $\alpha / \beta$ glycine receptors regulate excitability in parvalbumin-expressing dorsal horn neurons through phasic and tonic glycinergic inhibition. J. Physiol. 595, 7185-7202. doi: 10.1113/jp274926

Graham, B. A., Brichta, A. M., and Callister, R. J. (2004). in vivo responses of mouse superficial dorsal horn neurones to both current injection and peripheral cutaneous stimulation. J. Physiol. 561, 749-763. doi: 10.1113/jphysiol.2004. 072645

Greaves, D. S., Dufresne, M. J., Fackrell, H. B., and Warner, A. H. (1991). Age-related changes and tissue distribution of parvalbumin in normal and dystrophic mice of strain 129 ReJ. Muscle Nerve 14, 543-552. doi: 10.1002/mus. 880140609

Haberberger, R. V., Barry, C., Dominguez, N., and Matusica, D. (2019). Human dorsal root ganglia. Front. Cell. Neurosci. 13:271. doi: 10.3389/fncel.2019. 00271

Hayar, A., Gu, C., and Al-Chaer, E. D. (2008). An improved method for patch clamp recording and calcium imaging of neurons in the intact dorsal root ganglion in rats. J. Neurosci. Methods 173, 74-82. doi: 10.1016/j.jneumeth.2008. 05.023

Honda, C. N. (1995). Differential distribution of calbindin-D28k and parvalbumin in somatic and visceral sensory neurons. Neuroscience 68, 883-892. doi: 10.1016/0306-4522(95)00180-q

Horwitz, G. C., Risner-Janiczek, J. R., Jones, S. M., and Holt, J. R. (2011). HCN channels expressed in the inner ear are necessary for normal balance function. J. Neurosci. 31, 16814-16825. doi: 10.1523/JNEUROSCI.3064-11.2011

Hu, P., and McLachlan, E. M. (2002). Macrophage and lymphocyte invasion of dorsal root ganglia after peripheral nerve lesions in the rat. Neuroscience 112, 23-38. doi: 10.1016/s0306-4522(02)00065-9

Hughes, D. I., Boyle, K. A., Kinnon, C. M., Bilsland, C., Quayle, J. A., Callister, R. J., et al. (2013). HCN4 subunit expression in fast-spiking interneurons of the rat spinal cord and hippocampus. Neuroscience 237, 7-18. doi: 10.1016/j. neuroscience.2013.01.028

Hughes, D. I., Sikander, S., Kinnon, C. M., Boyle, K. A., Watanabe, M., Callister, R. J., et al. (2012). Morphological, neurochemical and electrophysiological features of parvalbumin-expressing cells: a likely source of axo-axonic inputs in the mouse spinal dorsal horn. J. Physiol. 590, 3927-3951. doi: 10.1113/jphysiol.2012.235655

Ichikawa, H., Deguchi, T., Nakago, T., Jacobowitz, D. M., and Sugimoto, T. (1994). Parvalbumin, calretinin and carbonic anhydrase in the trigeminal and spinal primary neurons of the rat. Brain Res. 655, 241-245. doi: 10.1016/00068993(94)91620-9

Ichikawa, H., Mo, Z., Xiang, M., and Sugimoto, T. (2004). Effect of Brn-3a deficiency on parvalbumin-immunoreactive primary sensory neurons in the dorsal root ganglion. Dev. Brain Res. 150, 41-45. doi: 10.1016/j.devbrainres. 2004.02.004

Jankowski, M. P., Rau, K. K., Ekmann, K. M., Anderson, C. E., and Koerber, H. R. (2013). Comprehensive phenotyping of group III and IV muscle afferents in mouse. J. Neurophysiol. 109, 2374-2381. doi: 10.1152/jn.01067.2012

Jiang, Y. Q., Sun, Q., Tu, H. Y., and Wan, Y. (2008). Characteristics of HCN channels and their participation in neuropathic pain. Neurochem. Res. 33, 1979-1989. doi: 10.1007/s11064-008-9717-6

Kim, G. H., Suzuki, S., and Kanda, K. (2007). Age-related physiological and morphological changes of muscle spindles in rats. J. Physiol. 582, 525-538. doi: $10.1113 /$ jphysiol.2007.130120

Klein, D., Bugl, B., Gunzburg, W. H., and Salmons, B. (2000). Accurate estimation of transduction efficiency necessitates a multiplex real-time PCR. Gene Ther. 7, 458-463. doi: 10.1038/sj.gt.3301112

Krames, E. S. (2014). The role of the dorsal root ganglion in the development of neuropathic pain. Pain Med. 15, 1669-1685. doi: 10.1111/pme.12413

Lainez, S., Tsantoulas, C., Biel, M., and McNaughton, P. A. (2019). HCN3 ion channels: roles in sensory neuronal excitability and pain. J. Physiol. 597, 4661-4675. doi: 10.1113/jp278211

Lawson, S. N. (2002). Phenotype and function of somatic primary afferent nociceptive neurones with C-, A $\delta$ - or A $\alpha / \beta$-fibres. Exp. physiol. 87, 239-244. doi: $10.1113 /$ eph 8702350
Lawson, S. N. (2005). "The peripheral sensory nervous system: dorsal root ganglion neurons," in Peripheral Neuropathy (Fourth Edition), eds P. J. Dyck and P. K. Thomas (Philadelphia, WB: Saunders), 163-202.

Ludwig, A., Budde, T., Stieber, J., Moosmang, S., Wahl, C., Holthoff, K., et al. (2003). Absence epilepsy and sinus dysrhythmia in mice lacking the pacemaker channel HCN2. EMBO J. 22, 216-224. doi: 10.1093/emboj/ cdg032

Manchikanti, L. (2000). Transforaminal lumbar epidural steroid injections. Pain Physician 3, 374-398.

Meyer, A. H., Katona, I., Blatow, M., Rozov, A., and Monyer, H. (2002). in vivo labeling of parvalbumin-positive interneurons and analysis of electrical coupling in identified neurons. J. Neurosci. 22, 7055-7064. doi: 10.1523/JNEUROSCI.22-16-07055.2002

Momin, A., Cadiou, H., Mason, A., and McNaughton, P. A. (2008). Role of the hyperpolarization-activated current Ih in somatosensory neurons. J. Physiol. 586, 5911-5929. doi: 10.1113/jphysiol.2008.163154

Moosmang, S., Stieber, J., Zong, X., Biel, M., Hofmann, F., and Ludwig, A. (2001). Cellular expression and functional characterization of four hyperpolarization-activated pacemaker channels in cardiac and neuronal tissues. Eur. J. Biochem. 268, 1646-1652. doi: 10.1046/j.1432-1327.2001. 02036.x

Nash, T. P. (1986). Percutaneous radiofrequency lesioning of dorsal root ganglia for intractable pain. Pain 24, 67-73. doi: 10.1016/0304-3959(86) 90027-8

Nolan, M. F., Malleret, G., Lee, K. H., Gibbs, E., Dudman, J. T., Santoro, B., et al. (2003). The hyperpolarization-activated HCN1 channel is important for motor learning and neuronal integration by cerebellar Purkinje cells. Cell 115, 551-564. doi: 10.1016/s0092-8674(03)00884-5

Notomi, T., and Shigemoto, R. (2004). Immunohistochemical localization of Ih channel subunits, HCN1-4, in the rat brain. J. Comp. Neurol. 471, 241-276. doi: 10.1002/cne.11039

Pape, H. C. (1996). Queer current and pacemaker: the hyperpolarizationactivated cation current in neurons. Annu. Rev. Physiol. 58, 299-327. doi: 10.1146/annurev.ph.58.030196.001503

Pape, H. C., and McCormick, D. A. (1989). Noradrenaline and serotonin selectively modulate thalamic burst firing by enhancing a hyperpolarizationactivated cation current. Nature 340, 715-718. doi: 10.1038/34 $0715 \mathrm{a} 0$

Rosant, C., Nagel, M. D., and Pérot, C. (2007). Aging affects passive stiffness and spindle function of the rat soleus muscle. Exp. Gerontol. 42, 301-308. doi: 10.1016/j.exger.2006.10.007

Scroggs, R. S., Todorovic, S. M., Anderson, E. G., and Fox, A. P. (1994). Variation in IH, IIR, and ILEAK between acutely isolated adult rat dorsal root ganglion neurons of different size. J. Neurophysiol. 71, 271-279. doi: 10.1152/jn.1994.71. 1.271

Stevens, D. R., Seifert, R., Bufe, B., Müller, F., Kremmer, E., Gauss, R., et al. (2001). Hyperpolarization-activated channels HCN1 and HCN4 mediate responses to sour stimuli. Nature 413, 631-635. doi: 10.1038/350 98087

Tsantoulas, C., Laínez, S., Wong, S., Mehta, I., Vilar, B., and McNaughton, P. A. (2017). Hyperpolarization-activated cyclic nucleotide-gated 2 (HCN2) ion channels drive pain in mouse models of diabetic neuropathy. Sci. Transl. Med. 9:eaam6072. doi: 10.1126/scitranslmed.aam6072

Turrigiano, G., Abbott, L. F., and Marder, E. (1994). Activity-dependent changes in the intrinsic properties of cultured neurons. Science 264, 974-977. doi: $10.1126 /$ science. 8178157

Vad, V. B., Bhat, A. L., Lutz, G. E., and Cammisa, F. (2002). Transforaminal epidural steroid injections in lumbosacral radiculopathy: a prospective randomized study. Spine 27, 11-16. doi: 10.1097/00007632-20020101000005

Van Zundert, J., Patijn, J., Kessels, A., Lamé, I., van Suijlekom, H., and van Kleef, M. (2007). Pulsed radiofrequency adjacent to the cervical dorsal root ganglion in chronic cervical radicular pain: a double blind sham controlled randomized clinical trial. Pain 127, 173-182. doi: 10.1016/j.pain.2006. 09.002

Wang, Z., Van den Berg, R. J., and Ypey, D. L. (1994). Resting membrane potentials and excitability at different regions of rat dorsal root ganglion 
neurons in culture. Neuroscience 60, 245-254. doi: 10.1016/0306-4522(94) 90218-6

Werner, M., Van De Water, T. R., Andersson, T., Arnoldsson, G., and Berggren, D. (2012). Morphological and morphometric characteristics of vestibular hair cells and support cells in long term cultures of rat utricle explants. Hear. Res. 283, 107-116. doi: 10.1016/j.heares.2011.11.003

Wingert, J. R., Welder, C., and Foo, P. (2014). Age-related hip proprioception declines: effects on postural sway and dynamic balance. Arch. Phys. Med. Rehabil. 95, 253-261. doi: 10.1016/j.apmr.2013.08.012

Woodbury, C. J., Ritter, A. M., and Koerber, H. R. (2001). Central anatomy of individual rapidly adapting low-threshold mechanoreceptors innervating the "hairy" skin of newborn mice: early maturation of hair follicle afferents. J. Comp. Neurol. 436, 304-323. doi: 10.1002/cne.1069

Wu, X., Liao, L., Liu, X., Luo, F., Yang, T., and Li, C. (2012). Is ZD7288 a selective blocker of hyperpolarization-activated cyclic nucleotide-gated channel currents? Channels 6, 438-442. doi: 10.4161/chan.22209

Xu, Z. Q., Zhang, X., Grillner, S., and Hökfelt, T. (1997). Electrophysiological studies on rat dorsal root ganglion neurons after peripheral axotomy: changes in responses to neuropeptides. Proc. Natl. Acad. Sci. U S A 94, 13262-13266. doi: 10.1073 /pnas.94.24.13262
Yawo, H. (1989). Rectification of synaptic and acetylcholine currents in the mouse submandibular ganglion cells. J. Physiol. 417, 307-322. doi: 10.1113/jphysiol. 1989.sp017803

Young, G. T., Emery, E. C., Mooney, E. R., Tsantoulas, C., and McNaughton, P. A. (2014). Inflammatory and neuropathic pain are rapidly suppressed by peripheral block of hyperpolarisation-activated cyclic nucleotidegated ion channels. Pain 155, 1708-1719. doi: 10.1016/j.pain.2014. 05.021

Conflict of Interest: The authors declare that the research was conducted in the absence of any commercial or financial relationships that could be construed as a potential conflict of interest.

Copyright () 2020 Madden, Davies, Boyle, Iredale, Browne, Callister, Smith, Jobling, Hughes and Graham. This is an open-access article distributed under the terms of the Creative Commons Attribution License (CC BY). The use, distribution or reproduction in other forums is permitted, provided the original author(s) and the copyright owner(s) are credited and that the original publication in this journal is cited, in accordance with accepted academic practice. No use, distribution or reproduction is permitted which does not comply with these terms. 